\title{
Possible dependence between the total solar irradiance and di- methylsulphide
}

\author{
B. Mendoza ${ }^{1 *}$, E. L. Flores-Márquez ${ }^{1}$, A. Ramírez-Rojas ${ }^{2}$ and A. Martínez-Arroyo ${ }^{3}$ \\ ${ }^{I}$ Instituto de Geofísica, Universidad Nacional Autónoma de México, Mexico City, Mexico \\ ${ }^{2}$ Área de Física de Procesos Irreversibles, Universidad Autónoma Metropolitana Azcapotzalco, Mexico City, Mexico \\ ${ }^{3}$ Centro de Ciencias de la Atmósfera, Universidad Nacional Autónoma de México, Mexico City, Mexico
}

Received: June 18, 2008; accepted: May 12, 2009

\begin{abstract}
Resumen
La variabilidad solar es una de las principales influencias naturales del clima terrestre, y que afecta profundamente a los procesos biológicos. Se ha propuesto que algunos de estos procesos biológicos alteran el albedo y por tanto tienen un impacto en el clima. En este trabajo investigamos la relación entre la irradiancia total solar (ITS) y la concentración de Dimetilsulfuro (DMS), que es producido por algas marinas. El DMS se ha mencionado frecuentemente como un forzamiento climático a través de su efecto en las nubes y por tanto en el albedo. En el presente trabajo encontramos que las series temporales de la IST y el DMS muestran una correlación. Para ello utilizamos un esquema probabilístico, la Función de Información Mutua (FIM), que es una medida de la dependencia entre los parámetros de interés. La FIM presenta una dependencia con el ciclo solar: valores mayores aparecen durante épocas de baja actividad solar (épocas de menor IST), mientras que los valores menores se presentan durante tiempos de alta actividad solar (mayor IST). En otras palabras, la dependencia entre IST y DMS es más fuerte durante épocas de actividad solar menor que durante actividad solar mayor.
\end{abstract}

Palabras clave: Función de información mutua, dimetilsulfuro, irradiancia solar total, actividad solar, relaciones Sol-Tierra.

\begin{abstract}
Solar variability is one of the main natural influences on the Earth's climate. Biological processes are profoundly affected by the solar irradiance. Some of these processes have been proposed to change the cloud albedo and therefore impact the climate. Here we investigate the relation between the total solar irradiance (TSI) and the global concentration of Dimethylsulphide (DMS), produced by plancktonic algae in seawater. DMS has been frequently mentioned as a forcing of climate through its effect on clouds and therefore on albedo. In the present work we attempt to find the relation between TSI and DMS. We found that the TSI and the DMS production data series display a correlation. A probabilistic scheme is introduced, the Mutual Information Function (MIF) which is a measure of the dependence between the parameters of interest. The MIF seems to present solar cycle dependence: larger values during lower solar activity times (lower TSI times) than during higher solar activity epochs (higher TSI epochs). Or in other words, the dependence between TSI and DMS is stronger during lower solar activity times than during higher solar activity epochs.
\end{abstract}

Key words: Mutual information function, dimethylsulphide, total solar irradiance, solar activity, Sun-Earth relations.

\section{Introduction}

The solar radiation is the fundamental source of energy that drives the Earth's climate and sustains life. Several attempts have been made to estimate the impact of the Total Solar Irradiance (TSI) on climate (Lean et al., 1995; Cubasch and Voss, 2000; Shindell et al., 2006; Lockwood and Fröhlich, 2007). However, in the last few decades, the changes measured in TSI are considered too small to explain the observed climate changes (Stott et al., 2003). Therefore, other mechanisms linking Sun and climate have been proposed: the ultraviolet (UV) radiation changes that could alter the tropospheric Hadley circulation affecting the equator-to-pole energy transport (Haigh,
1999; Shindell et al., 1999), the solar wind modulation of the global electric circuit (Tinsley, 2000) or the galactic cosmic rays that affect the electrofreezing processes (Tinsley and Deen, 1991) or the Earth's radiation budget (Pudovkin and Veretenko, 1995; Marsh and Svensmark, 2000; Pallé-Bagó and Butler, 2000; Usoskin et al., 2004; Svensmark, 2007).

Clouds have a major impact on the heat and radiation budget of the atmosphere as they modify the Earth's albedo. However to form a cloud, water vapour requires a condensation nucleus on which to condensate. It has been proposed that Dimethylsulphide (DMS) produced by planktonic algae in seawater (Charlson et al., 1987) 
could change the Earth's radiation budget, by producing cloud condensation nuclei (CCN).

According to several authors the major source of CCN over the oceans is Dimethylsulphide (DMS) (e.g. Andreae and Crutzen, 1997): dimethylsulfoniopropionate in phytoplankton cells is released into the water column where it is transformed into DMS. DMS diffuses through the sea surface to the atmosphere where it is oxidized to form $\mathrm{SO}_{2}$; this compound can be oxidized to $\mathrm{H}_{2} \mathrm{SO}_{4}$ that forms sulphate particles which act as $\mathrm{CCN}$.

The DMS concentration is controlled by the phytoplankton biomass and by a web of ecological and biogeochemical processes driven by the geophysical context (Simó, 2001). Solar radiation is a primary forcing of the geophysical context, and responsible for the growth of the phytoplankton communities.

The DMS, solar radiation and cloud albedo are hypothesized to have a feedback interaction (Charlson $e t$ al., 1987; Shaw et al., 1998; Gunson et al., 2006). This feedback can be either negative or positive, a negative feedback process requires a correlation between solar irradiance and DMS: increases in solar irradiance reaching the sea surface increase DMS augmenting the CCN and the albedo, an overall increased albedo produces a decrease of the irradiance reaching the sea surface and a cooling. A positive feedback requires an anti-correlation between solar irradiance and DMS: increases in solar irradiance produce a decrease of DMS, of CCN and albedo, a net reduced albedo allows more radiation to be absorbed producing a heating. Then a basic step of this feedback process is the type of relation between TSI and DMS.

At seasonal time scales, a first attempt to find a relations between a global database of DMS concentration and several geophysical parameters such as wind speed and sea surface temperature (SST) was carried out by Kettle et al. (1999) along 1972-1997. The authors sought linear correlations unsuccessfully. More recent quantitative studies (Simó and Dachs, 2002; Simó and Vallina, 2007; Vallina et al., 2007) concluded that at seasonal time scales, the DMS/TSI relation favours a climate negative feedback. Another study (Larsen, 2005) based on a conceptual model, proposed a positive feedback.

Moreover, several studies performed along few days and using samples from very localized regions, show that the seasonal and regional production of DMS is significantly influenced by UV radiation (Toole et al., 2006). Some of them report increases of DMS with exposure to UV (Sunda et al., 2002; Slezak and Herndl, 2003; Toole and Siegel, 2004). In contrast other studies found a decrease of DMS with increased UV (Hefu and
Kirst, 1997; Sakka et al., 1997; Kniventon et al., 2003).

In this context a basic question is then to find the type of relationship between TSI and DMS.

The quantitative aspects of the previous studies relating DMS and TSI mentioned above, focused on finding linear regression coefficients between the involved time series. However, given the complexity of the systems, linear correlations between DMS and TSI are not necessarily expected. Under these circumstances a standard statistical treatment of the data is not very appropriate.

In the present work we attempt to find the relation between TSI and DMS taking an alternative approach that consists in obtaining a measure of the global dependence between two parameters of interest (Dionisio et al., 2004). The mutual information function (MIF) (Matsuda, 1999) is particularly suitable for this purpose.

Also, the quantification of the relation between DMS and TSI could be the bases of another mechanism linking solar activity and climate.

The paper is organized as follows: in section 2 a description of the time series is given. Section 3 presents the statistical analysis, including a spectral analysis. Section 4 explains the MIF method. Section 5 describes the MIF calculation, in Section 6 we discuss the results and finally in section 7 we present our conclusions.

\section{TSI and DMS data series}

The TSI data time series were obtained from the National Geophysical Data Center (NGDC; http://www. ngdc.noaa.gov/). This data base has been compiled from many satellites since 1978 (http://www.ngdc.noaa.gov/ stp/SOLAR/ftpsolarirradiance.html). In particular we used the data provided by the Active Cavity Radiometer Irradiance Monitor (ACRIM) on board of the Solar Maximum Mission satellite; the data set is displayed as the daily-recorded variability of the TSI, starting from 1980 to 1997 (Fig.1a). The DMS data set was obtained from the site http://www.dss.ucar.edu/datasets. The original data series in this web site contains the DMS measurements collected in the global oceans during 1972-1998 and are given as raw data samples (Fig.1b). The sequence of data presents important data gaps in space and time, more details are given in Kettle et al. (1999).

\section{TSI and DMS statistical analysis}

For the DMS series, we use the average daily data. As there are data gaps we performed a previous treatment to the DMS original data series (see Figs. 2a and b) by 
Geofis. Int. 48 (4), 2009
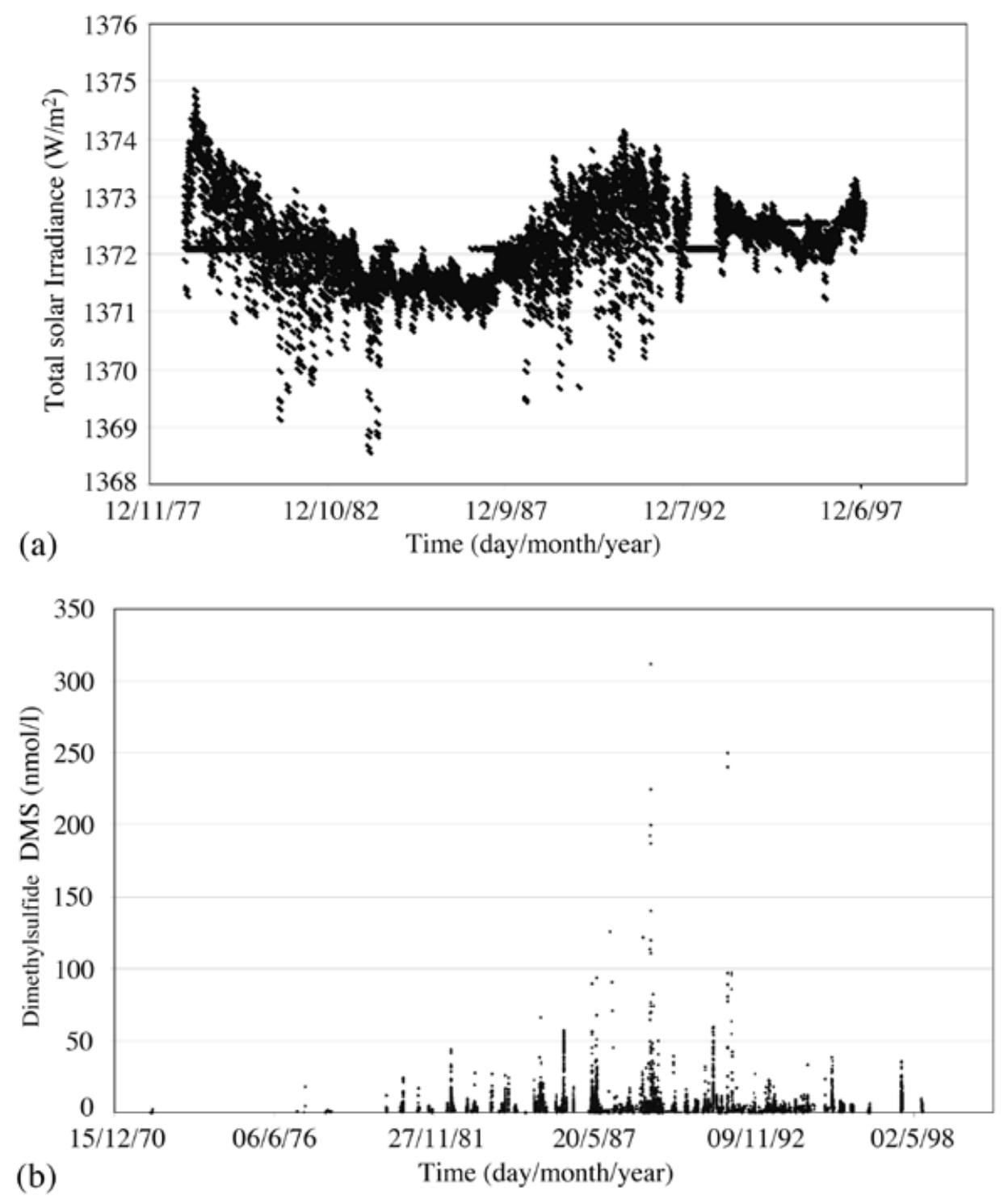

Fig.1. Original data bases. a) The total solar irradiance from 1980 to 1997 obtained from the web site http://www.ngdc.noaa. gov/stp/SOLAR/ftpsolarirradiance.html; b) The DMS measurements collected from the global oceans from 1972 to 1998 (15748 samples). They were obtained from http://www.dss.ucar.edu/datasets.

applying a moving average criterion to short periods with data gaps. However, for longer periods with data gaps this procedure is not applicable, this is the case for the DMS series where we detected seven gaps (see Fig.6): ${ }^{(1)}$ $11 / 7 / 80-5 / 4 / 81$; $^{(2)} 10 / 31 / 81-5 / 8 / 82$; $^{(3)} 7 / 31 / 82-1 / 4 / 83$; (4) $5 / 22 / 83-11 / 6 / 83$; (5) $9 / 13 / 86$ - $3 / 23 / 87$; (6) $12 / 13 / 92$ $1 / 20 / 94$; ${ }^{(7)} 11 / 6 / 96$ - 12/3/97. As we are mainly limited by the DMS data, we worked with the period containing the most numerous DMS observations: 1980-1997 (see Fig. 1b).

In order to verify the confidence of the selected period, from 1980 to 1997, a spectral analysis was performed on the TSI (Fig. 3). This ensures that no relevant information of the TSI series was lost when taking a shorter time span. Five important peaks appear with periodicities of: 9.6, 5.9, $3.9,2.5$, and 1.06 years respectively. These periodicities reproduce the most conspicuous ones observed in the solar activity (e.g. Polygiannakis et al., 2003).

We applied a linear autocorrelation analysis to the TSI and DMS series independently, and subsequently a standard cross-correlation was calculated between them. The TSI and DMS autocorrelations are depicted in Fig. 4. The autocorrelation of TSI time series (Fig. 4a) displays a long-range power law-like autocorrelation behavior 
$\mathrm{C}(\tau) \propto \tau^{-0,108}$. Typically this behavior indicates a fractal structure in the time series and consequently nonlinear properties.

Due to the fact that the DMS data were monitored unevenly in different sea world sites, the autocorrelation was computed for different segments and for the complete series, observing the same kind of behavior in all of them; each one shows a short-range correlation, with a fastdecaying time delay of approximately 20 days (see Fig. $4 \mathrm{~b}$ ); for a longer time delay an uncorrelated behavior is found.

A standard calculation of the cross correlation between DMS and TSI is shown in Fig. 5a. In this case a complex relation is observed; firstly a quasi-periodic behavior is depicted however a linear cross-correlation cannot be distinguished. Moreover, the scatter plot, showed in Fig. $5 \mathrm{~b}$, indicates a poor linear cross-correlation coefficient of $r=-0.0067$. We would like to point out that we obtain these results using an annual global data base, correlations or anticorrelations between DMS and TSI are not ruled out when using regional data or seasonal time scales. We already know that the TSI and DMS show dependence (Fig. 5a) and that their relation is non-linear (Fig. 5b). However, we would like to have more information and the MIF is a suitable alternative to achieve this.

\section{Mutual information function}

The MIF quantifies a global dependence between two variables. Some other interpretations are given in the literature, for instance the MIF represents the amount of information stored between two variables, another one considers the MIF as a measurement of the predictability of one variable by knowing the other one (Grosse et al., 2000). Clearly, these interpretations are related directly with the notion of dependence or correlation $(\mathrm{Li}$, 1990). Although the concept is the same, an important difference between the MIF and the correlation function deserves to be considered. While the MIF is able to give information for both numerical and symbolic sequences, the correlation function can be applied only to analyze numerical sequences evenly monitored. Moreover, the theoretical basis of the MIF in terms of the joint entropy (Shannon, 1948), allows to characterize the level of correlation. Finally, another advantage of the MIF is the possibility to perform the analysis even if the time series have data gaps in a given time span because the MIF is a punctual analysis in the window time.

The mutual information function $\mathrm{I}(\mathrm{A}, \mathrm{B})$ is defined as follows: Consider two physical systems A and B with a finite number of accessible states $\{a\}$ and $\{b\}$ respectively. Let $p(a)$ to be the probability of finding the system $A$ in the state $a, q(b)$ denote the probability of finding the system B in state $b$, and $p(a, b)$ denote the joint probability of finding the compound system $(\mathrm{A}, \mathrm{B})$ in the joint state $(\mathrm{a}, \mathrm{b})$.

For each system, the corresponding entropies are defined in terms of the probabilities by:

$$
\begin{aligned}
& H[A]=-\sum_{a} p(a) \log p(a) \\
& H[B]=-\sum_{a} q(b) \log q(b) \\
& H[A B]=-\sum_{a, b} p(a, b) \log p(a, b)
\end{aligned}
$$

Then the MIF is defined as:

$$
I(A, B)=\mathrm{H}[A]+\mathrm{H}[B]-\mathrm{H}[A B]
$$

or explicitly in terms of the joint probability:

$$
I(A B)=-\sum_{a, b} p(a, b) \log \frac{p(a, b)}{p(a) q(b)}
$$

Or explicitly in terms of the joint probability, can be written as:

When A and B are statistically independent, the mutual information between them is zero, that is, $I(A, B)$ $=0$. When there is dependence, the MIF between them is positive and, the MIF must satisfy the condition $0 \leq I$ $(A, B) \min \{H[A], H[B]\}$ (Matsuda, 1999), in this sense the MIF characterize the degree of correlation between both systems

Another advantages of the MIF in comparison with the classical correlation function, are: (i) The correlation function only measures linear correlations, MIF is able to characterize a global dependence (Matsuda, 1999); (ii) MIF remains invariant for transformation of $a, b$; (iii) the correlation function relies on an assignment of numerical values but MIF can be calculated directly from a set of symbols associated with the accessible states of the systems. When a signal is symbolized some dynamical features can be lost, however we are interested to find long-range information instead of the dynamical behavior of the signals.

\section{The MIF between TSI and DMS}

We define the time series for DMS $\left\{S_{d m s}(t)\right\}$, and for TSI $\left\{S_{T I}(t)\right\}$. The variables are symbolized as follow: $X_{\mathrm{TI}}$ is the variable associated to TSI and $\mathrm{Y}_{\mathrm{dms}}$ is the variable associated to DMS production. We defined two states for each series as follows: 


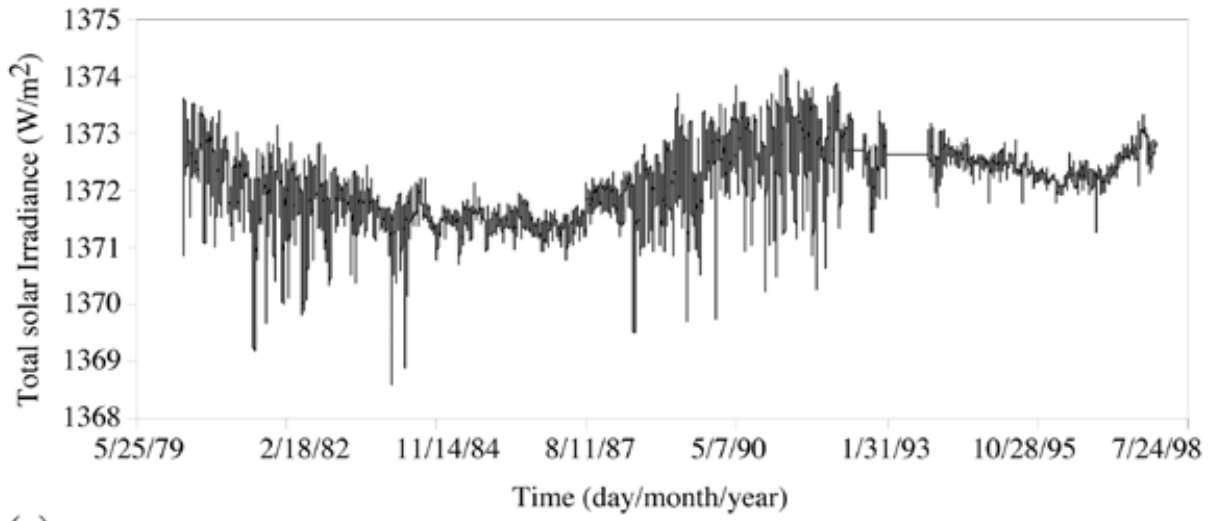

(a)

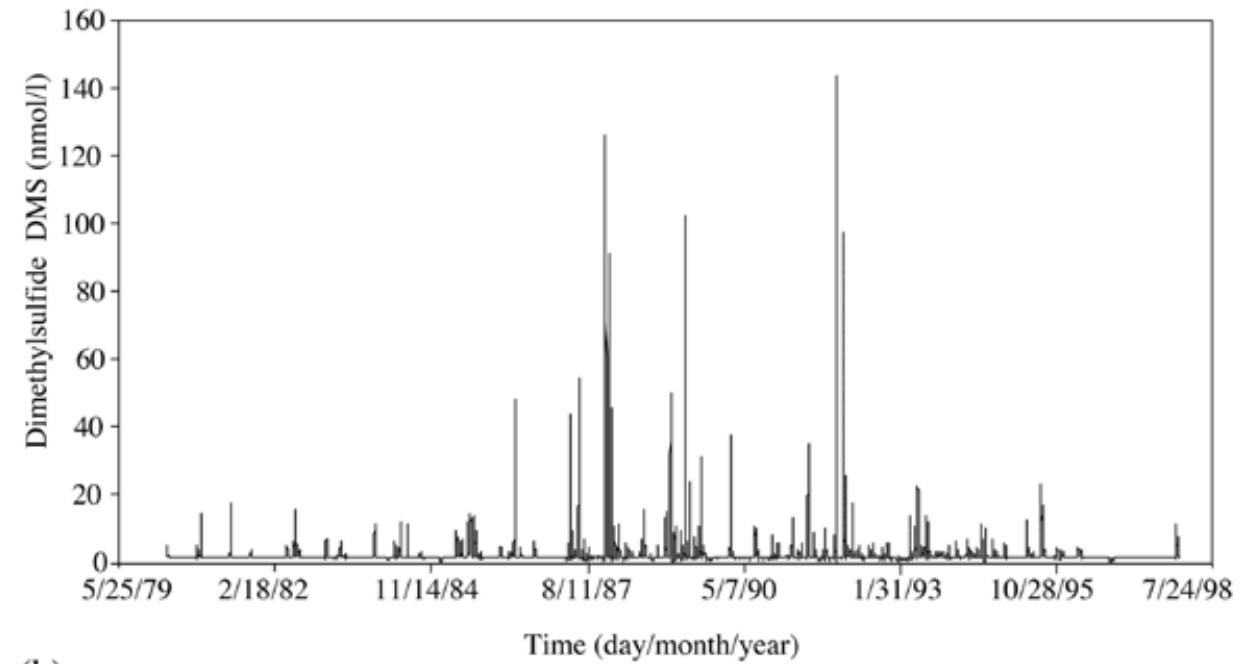

(b)

Fig. 2. Processed data series from 1980 to 1997. a) The TSI time series; b) The DMS production series.

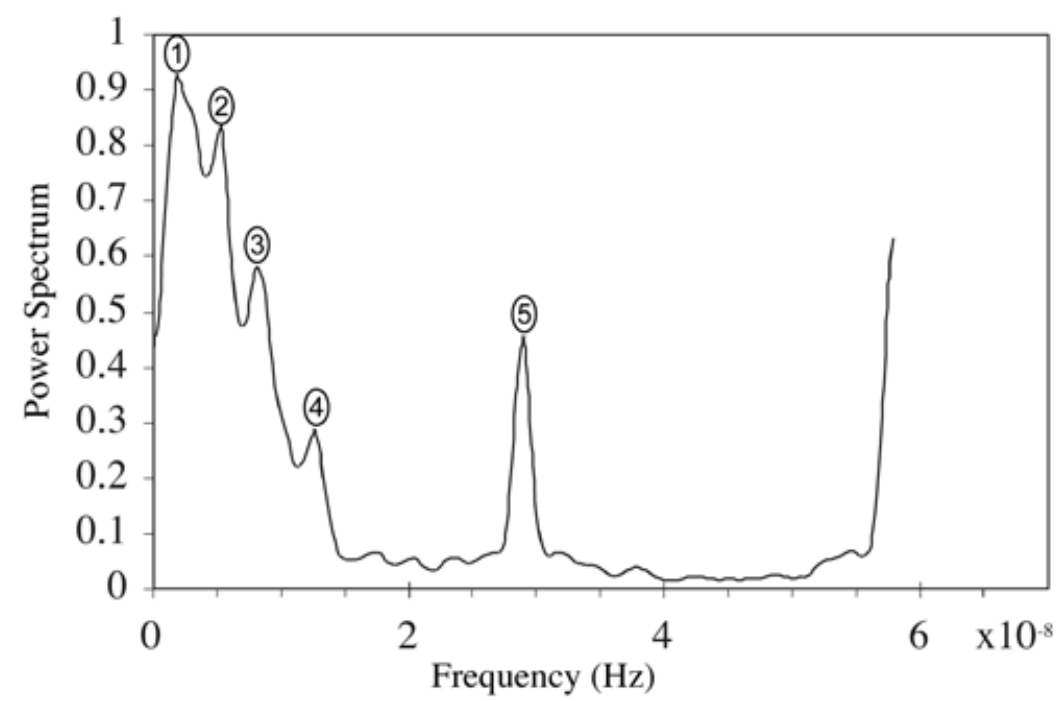

Fig. 3. Power spectrum plot of the TSI time series from 1980 to 1997, showing characteristic frequencies. 


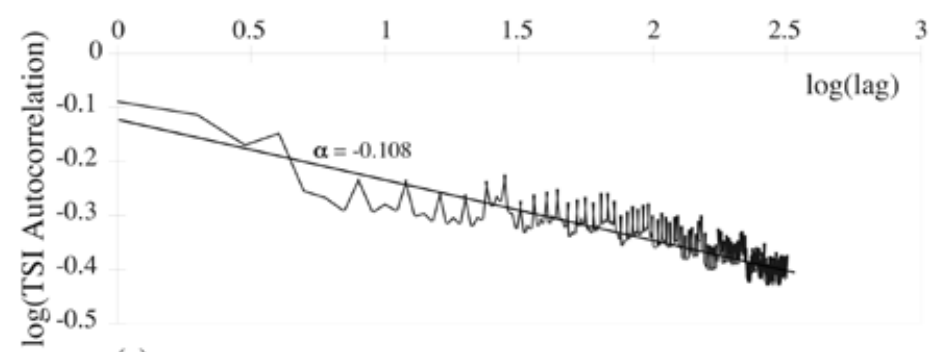

(a)

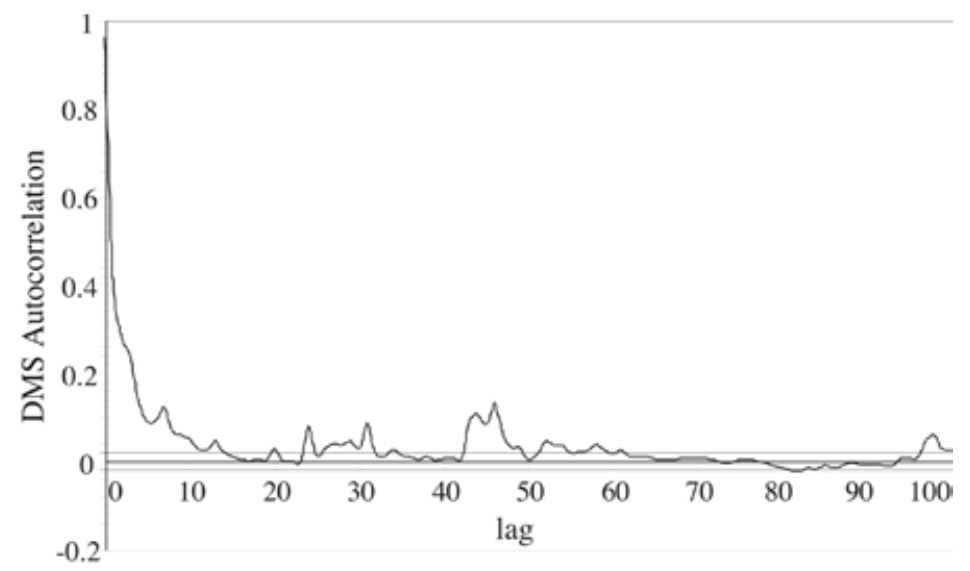

(b)

Fig. 4. Auto-correlation plots. a) The TSI data series (log scales); b) The DMS data series.

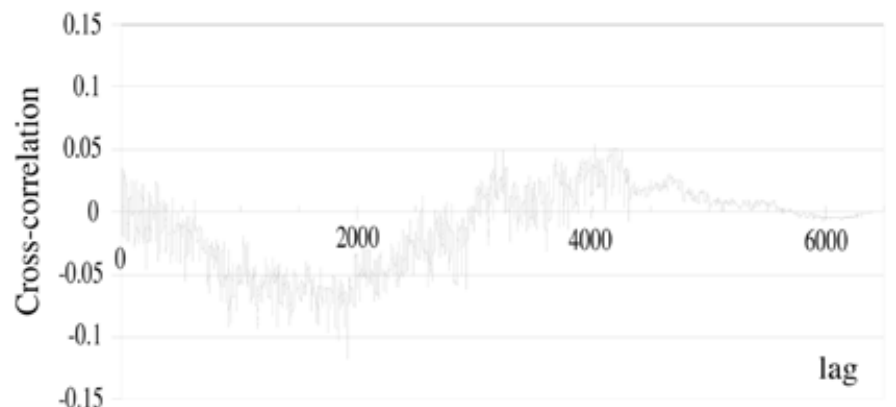

(a)

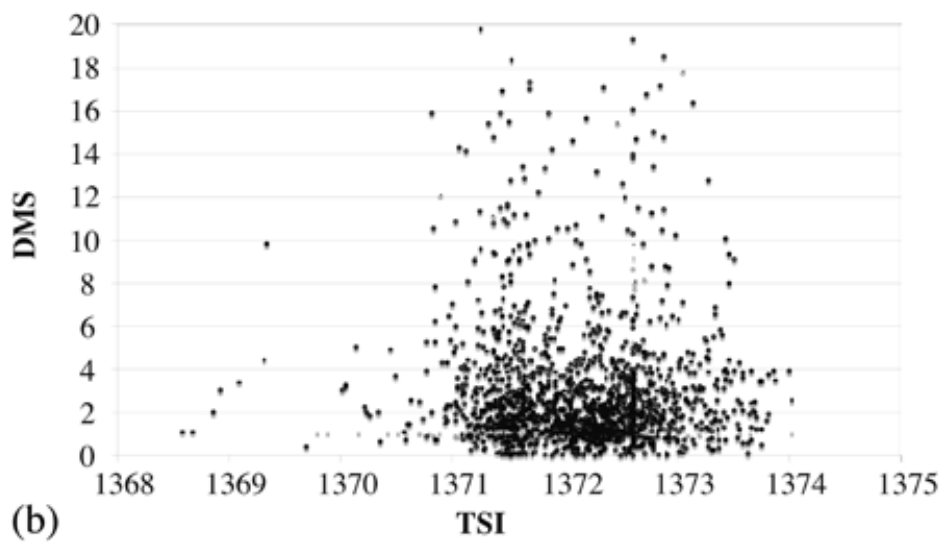

Fig. 5. a) The cross-correlation function between TSI and DMS time series; b) The scatter plot between TSI and DMS time series. 


$$
\begin{aligned}
& X_{T I}(t)=\left\{\begin{array}{l}
0 \text { if } S_{T I}(t)<\left\langle S_{T I}(t)\right\rangle \\
1 \text { otherwise }
\end{array}\right. \\
& Y_{d m s}(t)=\left\{\begin{array}{l}
0 \text { if } S_{d m s}(t)<\left\langle S_{d m s}(t)\right\rangle \\
1 \text { if } S_{d m s}(t)>\left\langle S_{d m s}(t)\right\rangle
\end{array}\right.
\end{aligned}
$$

Where $\langle\mathrm{s}\rangle$ represents the mean value over the complete time series.

One-month (30 days) windowing was considered, and for each window the probabilities $p(x)$ and $q(y)$ were calculated, here $\{x, y\}$ represent the accessible states of the variables $X_{T I}$ and $Y_{d m s}$ respectively. To compute the MIF, $I\left(X_{T P}, Y_{d m s}\right)$ from Eq. (2), the joint probability $p(x, y)$, was calculated following the algorithm proposed in Druzdzel
(1994). In fact, the joint probability should represent the internal interactions between all components of the systems. In terms of our variables the Eq. (2) is rewritten as:

$$
I\left(X_{T I}, Y_{d m s}\right)=\sum_{x} \sum_{y} p(x, y) \ln \frac{p(x, y)}{p(x) p(y)}
$$

The normalization condition must be satisfied:

$$
\sum_{x} p(x)=\sum_{x} \sum_{y} p(x, y)=1
$$

and

$$
\sum_{y} q(y)=\sum_{y} \sum_{x} p(x, y)=1
$$

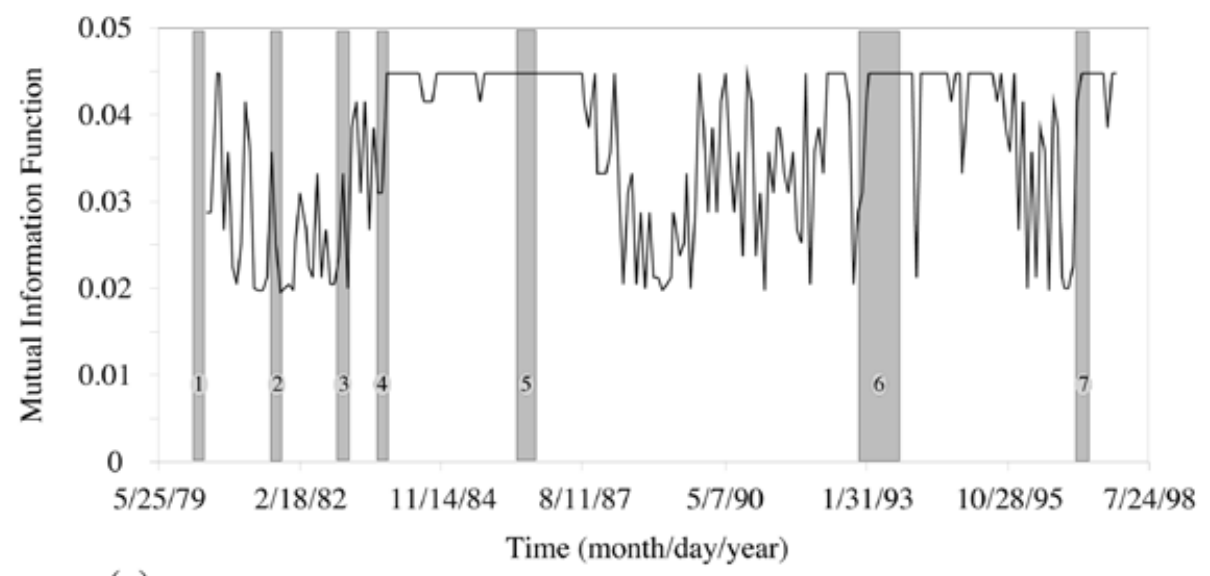

(a)

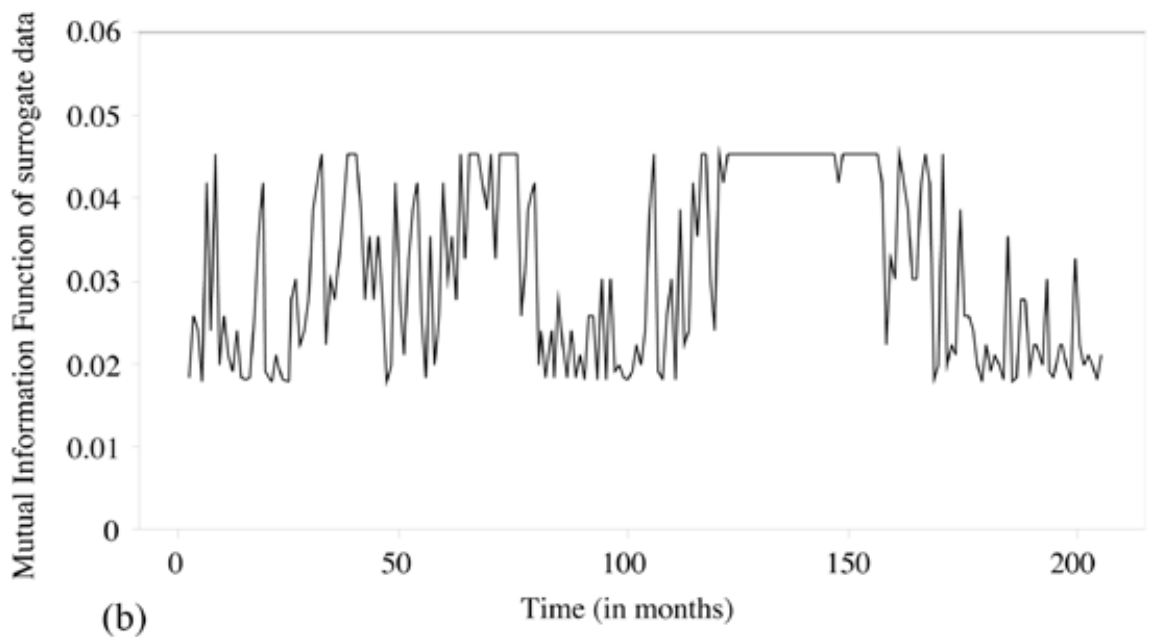

Fig. 6. a) The Mutual Information Function between TSI and DMS series. The vertical shaded bars are the seven DMS time gaps. b) The Mutual Information Function between the surrogate data series. 


\section{MIF results and discussion}

From Eq. (2), the MIF between TSI and DMS is calculated and presented in Fig. 6a. We also produced a surrogate (Schreiber and Smith, 2000) of both series (see Fig. 6b) as the resulting MIF shows a different structure from the previous one, this indicates that the analysis is statistically significant.

A global dependence between the DMS production and the TSI is observed in the sense that we always have MIF values larger than zero (see Fig. 6), however, we already found that the relation between DMS and TSI is non-linear (see Fig. 5). According to Fig. 6, from 1984 to 1988 and from 1992 to 1996, the MIF reaches its maximum values, indicating a strong relation of the series. The periods of low and highly variable relation are those between 1980 and before 1984, and after 1988 to before 1992. The time spans of 1984-1988 and 1992-1996 correspond to lower solar activity times compared with the time spans of 19801984 and 1988-1992. Then a dependence of MIF behavior with the sunspot cycle is suggested: the MIF values seem to be larger in times of lower solar activity, and decrease during times of higher solar activity. Or in other words, during lower solar activity times the dependence between DMS and TSI is stronger than in higher solar activity epochs. Moreover, it is well known the strong positive correlation between TSI and solar activity (Lean, 2000) therefore lower solar activity times are times of lower TSI and higher MIF values and viceversa.

Although a relation between DMA and TSI has been sought in previous works, an explicit association between DMS/TSI and the solar activity cycle has not been discussed. In this sense the present is the first work to do so, because we search for long term (not seasonal) global relations as the data time span goes from 1980 to 1997.

\section{Conclusions}

In order to quantify the global long-term dependence of the DMS production as function of TSI, a linear correlation was firstly sought. We found that the series show a very weak linear correlation coefficient. Then, a probabilistic scheme was introduced, the Mutual Information Function (MIF) formalism, in order to characterize the global correlation between the DMS production and the TSI.

An association between DMS/TSI and the solar activity cycle is suggested, the MIF seems to present a solar cycle dependence: maximum values are found between 1984 and 1988 and also from 1992 to 1996, which would imply that the MIF is stronger during lower solar activity times than during higher solar activity epochs. Then when TSI is lower the correlation with the global DMS attaints higher values and viceversa, but the relation between them is non-linear.

As mentioned in the Introduction, a basic step of the feedback process between DMS, cloud albedo and solar radiation, is to know if the relation between TSI and DMS is a correlation or an anti-correlation. The MIF between TSI and DMS does not provide information on the type of relation between these variables, it only indicates that the dependence between the variables (than can be a positive or negative relation) is higher during lower TSI times. Then we cannot yet answer if the feedback is either positive or negative, however we have given a step forward by showing that in fact there is a dependence between TSI and DMS and that this dependence in nonlinear.

\section{Bibliography}

Andreae, M. O. and P. J. Crutzen, 1997. Atmospheric aerosols: biogeochemical sources and role in atmospheric chemistry, Science 276, 1052-1058.

Charlson, R. J., J. E. Lovelock, M. O. Andreae and S. G.Warren, 1987. Oceanic phytoplankton, atmospheric sulfur, cloud albedo and climate: a geophysiological feedback, Nature 326, 655-661.

Cubasch, U. and R. Voss, 2000. The influence of total solar irradiance on climate, Space Sci. Rev. 94, 185-198.

Dionisio, A., R. Menezes and D. A. Mendes, 2004. Mutual Information: A measure of dependency for nonlinear time series, Physica A 344, 326-329.

Druzdzel, M. J., 1994. Some properties of joint probabilities distribution, in Proceedings of the $10^{\text {th }}$ annual conference on uncertainty and artificial intelligence (UAI-94), (Morgan Kaufmann Publishers Inc. CA, E.U.A, 1994) 187-194.

Grosse I., H. Hertzel, V. Buldyrev and H. E. Stanly, 2000. Species independence of mutual information in coding and non coding DNA, Phys. Rev. A 61, 5624-5629.

Gunson, J. R., S. A Spall, T. R. Anderson, A. Jones, I. J. Totterdell and M. J. Woodage, 2006. Climate sensitivity to ocean dimethylsulphide emissions, Geophys Res. Lett. 33, ID L07701, 10.1029/2005GL024982.

Haigh, J. D., 1999. A GCM study of climate change in response to the 11-year solar cycle, Q. J. R. Meteorol. Soc. 125, 871-892. 
Hefu, Y. and G. O. Kirst, 1997. Effects of UV radiation on DMS content and DMS formation of Phaeocystis Antartica, Polar Biol. 18, 402-409.

Kettle, A. J., M. O. Andreae, D. Amouroux, et al., 1999. A global data base of sea surface Dimethylsulfide (DMS) measurements and a procedure to predict sea surface DMS as a function of latitude, longitude and month, Global Biogeochem. Cycles 13, 399-444.

Kniventon, D. R., M. C. Todd, J. Sciare and N. Mihalopoulos, 2003. Variability of atmospheric dimethylsulphide over the southern Indian Ocean due to changes in ultraviolet radiation, Global Biogeochem. Cycles 17, 1096, doi: 10.1029/2003GB002033.

Larsen, S. H., 2005. Solar variability, dimethyl sulphide, clouds, and climate, Global Biogeochem. Cycles 19, GB1014.

Li, W., 1990. Mutual information function versus correlation functions, Journal of Statistical Physics 60, 823-837.

Lean, J. L., J. Beer and R. Bradley, 1995. Reconstruction of solar irradiance since 1610: implications for climate change, Geophys. Res. Lett. 22, 3195-3198.

Lean, J. L., 2000. Short term direct indices of solar variability, Space Sci. Rev. 94, 39-51.

Lockwood, M. and C. Fröhlich, 2007. Recent oppositely directed trends in solar climate forcings and the global mean surface air temperature, Proc. R. Soc. A, doi:10.1098/rspa.2007.1880.

Marsh, N. D. and H. H. Svensmark, 2000. Low cloud properties influenced by Cosmic Ray, Phys. Rev. Letts. 85, 5004-5007.

Matsuda, H., 1999. Physical nature of higher-order mutual information: intrinsic correlations and frustration, Physical Review E 62-3, 3096-3102.

Pallé-Bagó, E. and C. J. Butler, 2000. The influence of cosmic rays on terrestrial clouds and global warming, Astron. Geophys. 41, 418-422.

Pudovkin, M. I. and S. V. Veretenenko, 1995. Cloudiness decreases associated with Forbush decreases of galactic cosmic rays, J. Atm. Solar-Terr. Phys. 57, 1349-1355.

Polygiannakis, J., P. Preka-Papadema and X. Moussas, 2003. On signal-noise decomposition of time-series using the continuous wavelet transform: application to sunspot index, Mon. Not. R. Astron. Soc. 343, 725734.

Sakka, A., M. Gosselin, M. Levasseur, P. Monfort and S. Demers, 1997.Effects ofreducedultravioletradiation on aqueous concentrations of dimethylsulfoniopropionate during a microcosm study in the Lower St. Lawrence Estuary, Mar. Ecol. Prog. Ser. 149, 227-238.

Schreiber, T. and A. Smith, 2000. Surrogate time series, Physica D 142, 346-382.

Shannon, C. E., 1948. Bell. Syst. Tech. J. 379.

Shaw, G. E., R. L. Benner, W. Cantrell and D. Veazey, 1998. The regulation of climate: A sulfate particle feedback loop involving deep convection-An editorial essay, Clim. Change 39, 23-33.

Shindell, D. T., D. Rind, N. Balachandran, J. Lean, and P. Lonergan, 1999. Solar cycle variability, ozone and climate. Science 284, 305-308.

Shindell, D. T., G. Faluvegi, R. L. Miller, G. A. Schmidt and J. E. Hansen, 2006. Solar and anthropogenic forcing of tropical hydrology, Gephys. Res. Lett. 33, L24706, 10.1029/2006GL027468.

Simó, R., 2001. Production of atmpospheric sulfur by oceanic plankton: Biogeochemical, ecological and evolutionary links, Trends Ecol. Evol. 16, 287-294.

Simó, R. and J. J. Dachs, 2002. Global ocean emission of dymethylsulfide predicted from biogeophysical data, Global Biogeochem. Cycles, doi: 10.1029/2001GB001829.

Simó, R. and S. M. Vallina, 2007. Strong relationship between DMS and the solar radiation dose over the global surface ocean, Science 315, 506-508.

Slezak, D. and G. J. Herndl, 2003. Effects of ultraviolet and visible radiation on the cellular concentration of dimethylsulfoniopropionate (DMSP) in Emiliania huxleyi (strain L), Mar. Ecol. Prog. Ser. 246, 61-71.

Stott, P. A., G. S. Jones and J. F. B. Mitchell, 2003. Do models underestimate the solar contribution to recent climate changes? J. Clim. 16, 4079-4093.

Sunda, W., D. J. Kieber, R. P. Kiene and S. Huntsman, 2002. An antioxidant function for DMSP and DMS in marine algae, Nature 418, 317-320. 
Svensmark, H., 2007. Cosmoclimatology: a new theory emerges, Astron. and Geophys. 48, 18-24.

Tinsley, B. A. and G. W. Deen, 1991. Apparent tropospheric response to $\mathrm{MeV}-\mathrm{GeV}$ particle flux variations: A connection via electrofreezing of supercooled water in high level clouds? J. Geophys. Res. 96, 22283-22296.

Tinsley, B. A., 2000. Influence of solar wind on the global electric circuit, and inferred effects on cloud microphysics, temperature and dynamics in the troposphere, Space Sci. Rev. 94, 231-258.

Toole, D. A. and D. A. Siegel, 2004. Light-driven Cycling of Dimethylsulfide (DMS) in the Sargasso Sea: Closing the Loop, Geophys. Res. Lett., doi: 10.1029/2004GL019581.

Toole, D. A., D. Slezak, R. P. Kiene, D. J. Kieber and D. A., 2006. Effects of solar radiation on dimethylsulfide cycling in the western Atlantic Ocean, Deep-Sea Res. I, 53, 136-153.

Usoskin, I. G., N. Marsh, A. Kovaltsov, K. Mursula and O. G. Gladyssheva, 2004. Latitudinal dependence of low cloud amount on cosmic ray induced ionization, Geophys. Res. Lett. 31, doi: 10.1029/2004GL019507.

Vallina, S. M., R. Simó, S. Gassó, C. de Boyer-Montégut, E. del Río, E. Jurado and J. Dach, 2007. Analysis of a potential "solar radiation dose-dimethylsulfidecloud condensation nuclei" link from globally mapped seasonal correlations, Global Biogeochem. Cycles 21, GB2004, doi:10.1029/2006GB002787.

B. Mendoza ${ }^{*}$, E. L. Flores-Márquez ${ }^{1}$, A. Ramírez-Rojas $^{2}$ and A. Martínez-Arroyo ${ }^{3}$ ${ }^{1}$ Instituto de Geofísica, Universidad Nacional Autónoma de México, Ciudad Universitaria, Del. Coyoacán 04510, Mexico City, Mexico

${ }^{2}$ Área de Física de Procesos Irreversibles, Universidad Autónoma Metropolitana Azcapotzalco, Avenida San Pablo 180 Col. Reynosa, Azcapotzalco 02200, Mexico City, Mexico

${ }^{3}$ Centro de Ciencias de la Atmósfera, Universidad Nacional Autónoma de México, Ciudad Universitaria, Del. Coyoacán 04510, Mexico City, Mexico

*Corresponding author: blanca@geofisica.unam.mx 